\title{
Comparative Study of HBV Light and GR4J Conceptual Hydrological Models for Assessment of Impact of Climate Change on Water Availability of Awata River Watershed, Genale Dawa Basin:Southern Ethiopia
}

\author{
Tesfaye Gragn ${ }^{1 *} \quad$ Asfaw Kebede ${ }^{2} \quad$ Shimelis Berhanu $^{3}$ \\ 1. Bore Agricultural Research center, Oromia Agricultural Research institute, Ethiopia \\ 2. School of Water Resource and Environmental Engineering, Institute of Technology, Haramaya University, \\ Dire Dawa, Ethiopia \\ 3. Institute for Hydrogeology, Technical University of Freiberg, Gustav-Zeuner-Str. 12, Zi. 30509599 Freiberg, \\ Saxony, Germany
}

\begin{abstract}
This research was conducted to study impacts of climate change on water resource of Awata River watershed. Statistical Downscaling Model version 5.1.1 has been used to downscale the daily maximum temperature, minimum temperature, and precipitation in 30-year intervals from the second generation of the Earth System Model (CanESM2) under two Representative Concentration Pathways (RCP) Scenarios (RCP4.5 and RCP8.5). Climate change scenarios for precipitation and temperature were developed for two future periods 2018-2047 (2020s) and 2048-2077 (2050s). According to the projected climate data, the monthly minimum and maximum temperature are likely to have an increasing trend $+2.94^{\circ} \mathrm{C}$ and $2.25^{\circ} \mathrm{C}$ respectively. Regarding the rainfall change, under the RCP4.5 scenario the study shows annual average increment of by $26.8 \%$ and $35.1 \%$ at near (2020) and mid-term (2050) respectively. On monthly bases rainfall shows there is incensement in some months and decrease in some months. The HBV Light and GR4J hydrological models were successfully calibrated (2003-2012) and validated (2013-2017) using current climatic inputs and observed river flows. The overall performances of both models were good, at monthly time scale; on calibration $\left(\mathrm{R}^{2}=0.87\right.$ and NSE $\left.=0.78\right)$ and validation $\left(\mathrm{R}^{2}=0.85\right.$ and $\mathrm{NSE}=0.80)$ with HBV Light whereas, calibration $\left(\mathrm{R}^{2}=0.81\right.$ and $\left.\mathrm{NSE}=0.72\right)$ and validation $\left(\mathrm{R}^{2}=0.84\right.$ and $\mathrm{NSE}=$ 0.75 ) for GR4J model. Over the two projected periods (2018-2047 and 2048-2077) under both RCP4.5 and RCP8.5 scenario HBV-Light and GR4J models simulation results showed that the mean annual discharge will significantly increase related to the baseline periods (1988-2017). HBV light indicate the percentage increment of total average annual flow volume $7.3 \%$ (2018-2047) and 7.0\% (2048-2077) for RCP 4.5 scenario, and For RCP 8.5 scenario, the increment ranges between $7.7 \%$ (2018-2047) to 7.9\% (2048-2077). The GR4J model indicates the percentage increment of total average annual flow volume $6.4 \%(2018-2047)$ and $6.6 \%(2048-2077)$ for RCP 4.5 scenario, and For RCP 8.5 scenario, the increment ranges between 6.2\% (2018-2047) to 7.6\% (2048-2077). In conclusion increase in average total annual, seasonal and monthly flow volume is observed for periods which show a corresponding increases in mean annual, seasonal and monthly precipitation during scenario developments so that, future studies must recognize the over-all implication of climate change in the Awata watershed.
\end{abstract}

Keywords: Awata, Climate change, canESM2, HBV, GR4J, SDSM, Ethiopia.

DOI: 10.7176/JEES/9-9-01

Publication date:September $30^{\text {th }} 2019$

\section{INTRODUCTION}

The IPCC Fifth Assessment Report on Climate Change points out that over the past half century, almost all regions of the world have experienced a heating process, with global air temperatures increasing by $0.85^{\circ} \mathrm{C}$ over the period of 1880-2012 IPCC (2013). This climate change is associated with global warming that is induced by the increase in carbon dioxide and other radioactive trace gases in the atmosphere. In recent years, the focus of scientific investigations has increased over climate change caused by increasing concentrations of carbon dioxide and other trace gases in the atmosphere due to the fact that climate change has significant implications for the environment, ecosystems, water resources and virtually every aspect of human life (IPCC, 2001). The most important and immediate effects of global warming would be the changes in local and regional water availability, since the climate system is interactive with the hydrologic cycle (Arora and Boer, 1996).

As large proportion of the region's population depend on the rainfed agriculture, climate change impact is suffering in Sub-Saharan Africa (World Bank, 2015). With climate change the amount of rainfall in many parts of Africa is expected to decline while variability may increase dramatically (IPCC 2007). According to IPCC (2007) report, the population at risk of increased water stress in Africa is projected to be between 75-250 and 350-600 million people by 2020s and 2050s, respectively.

In Ethiopia in the last few decades, high temperature values were recorded in different parts of the country. The various General Circulation Model (GCM) results also suggest that future climatic change climatic elements 
will be significant. For instance, the average future change for the whole of Ethiopia for a 30-year period with A2 emissions shows warming in all four seasons in all regions, with annual warming in Ethiopia of $1.2^{\circ} \mathrm{C}$ with a range of $0.7-2.3^{\circ} \mathrm{C}$ by the $2020 \mathrm{~s}$, and by $2.2^{\circ} \mathrm{C}$ with a range of $1.4-2.9^{\circ} \mathrm{C}$ by the $2050 \mathrm{~s}$ (Conway and Schipper, 2011). So far, some studies have predicted long-term future climate change situations that could prevail up until the end of this century in Ethiopia (McSweeney et al., 2010). In general, in Ethiopia water shortages and related impacts causes loss of assets in the form of crops, livestock, and other productive capitals.

According to Tao et al. (2007), it would not be unfair to say that all kinds of models find their usefulness in different applications. Physically-based distributed-parameter models are complex in terms of structure and input requirements and can be expected to provide adequate results for a wide range of applications. On the other hand, simpler models which have a smaller range of applications can yield adequate results at a greatly reduced cost, provided that the objective function is suitable. It is therefore desirable to compare the differences in hydrological impacts of alternative climates resulting from the use of more hydrological models (at least two models) and recommend which one of the models is more suitable on a given topographic and climatic condition.

Awata watershed is under great pressure because of growing population and increasing demand of water mainly for irrigation, which is not practiced well currently in the watershed, and also a great demand for domestic and livestock water consumption purposes. No Impact assessment of climate change study had been performed for the Awata watershed of the Genale dawa basin, even though there have been studies conducted on other part of the Genale dawa basin (e.g. Shanka, 2017 and Kassa, 2014), which indicates that with respect to future climate in Genale Dawa basin there is high confidence temperature will increase and leading to increase evaporation. Therefore against to this background, it is paramount to study the climate change impacts on the water availability of Awata river watershed's in order to take the effect in to account by the policy and decision makers when planning water resource management. The objective of this study was comparative study of HBV light and GR4J conceptual hydrological models for assessment of impact of climate change on water availability of Awata River watershed.

\section{MATERIALS AND METHODS}

\subsection{Study Area}

Awata watershed which has a drainage area of $1513 \mathrm{~km}^{2}$ is located in Ganale Dawa River basin. Awata watershed is geographically lies between coordinates of $5^{\circ} 30^{\prime}$ to $6^{\circ} 30^{\prime} \mathrm{N}$ latitude and $38^{\circ} 20^{\prime}$ to $38^{\circ} 60^{\prime} \mathrm{E}$ longitude with an approximation altitude range between 1650 and $3025 \mathrm{~m}$.a.s.l. as it shown in Figure 1. The annual rainfall ranges between $820 \mathrm{~mm}$ and $1350 \mathrm{~mm}$. The monthly maximum temperature is between $19^{\circ} \mathrm{C}$ and $24^{\circ} \mathrm{C}$, and the monthly minimum temperature is between $8^{\circ} \mathrm{C}$ and $12^{\circ} \mathrm{C}$. The study area had been selected due to the reason that it is one of the major tributaries of Genale Dawa River and no impact assessment studies had been done on the watershed.

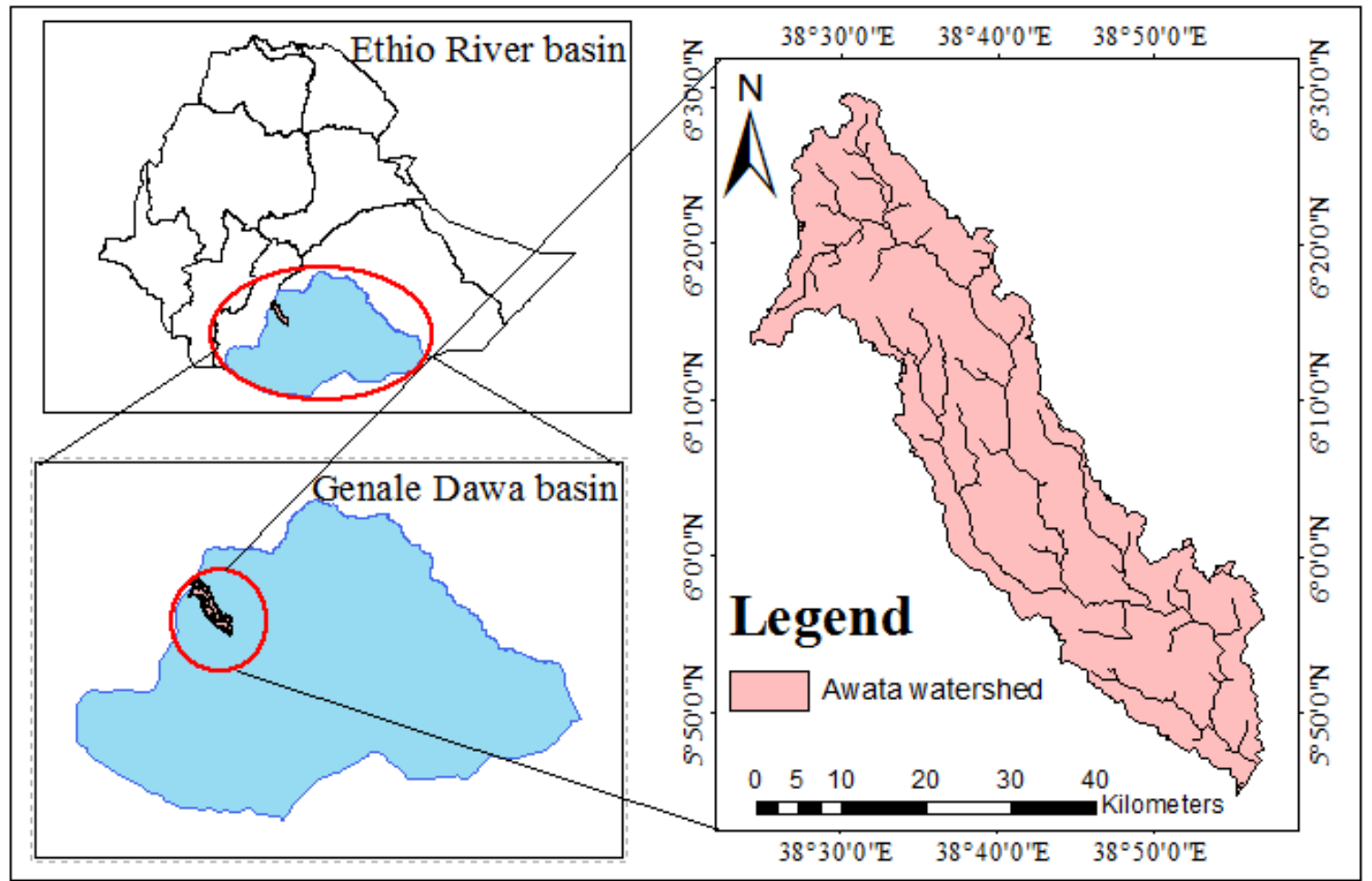

Figure 1. Location map of Awata watershed. 


\subsection{Methodology}

In this study, the output variables from canESM2 (second generation of the Earth System Model) for both emission scenarios of RCP4.5 and RCP8.5 were statistically downscaled by with Statistical Downscaling Model (SDSM) version 5.1.1. HBV-Light hydrological model was calibrated and validated using historical climate data of three stations (Hagere selam, Kibremengist and Yirba muda) and observed discharge data of Awata River. The downscaled future scenario 20 ensembles data of both RCP4.5 and RCP8.5 scenario were used as an input for HBV-Light model to assess watershed hydrological response to climate change.

\subsection{Data Types and Sources}

\subsubsection{Meteorological Data}

The required meteorological data of the study area was collected from the Ethiopian National Meteorology Agency (NMA). The long-term records daily meteorological data for 30 years (1988-2017) was obtained from three meteorological stations (Hagere selam, Kibremengist and Yirba muda) located in and nearby of the study area. Meteorological data collected were includes variables such as precipitation, minimum and Maximum temperature. All stations listed above contain daily rainfall and temperature data for at least 30 years. Therefore all stations were used for hydrological model development.

\subsubsection{Hydrological Data}

Stream flow data of Awata River was required for calibrating and validating of the HBV light model simulation. There is one main gauging station at the outlet of Awata River at Shakiso. Daily and average monthly based Stream flow Discharge data for the years 1988-2007 which have continuous record was collected from the Hydrology Department of Ministry of water irrigation and electricity of Ethiopia (MoWIE).

\subsection{Climate Model and Downscaling}

For this study the climate scenario data (RCP4.5 and RCP8.5) were extracted from canESM2 model based on longitude and latitude that had grid resolution of $2.5^{\circ}$ latitude by $3.75^{\circ}$ longitude. The coarser climate data (canESM2 output) further downscaled in to station level by using statistical downscaling model (SDSM version 5.1.1) and these downscaled data was taken directly as an input to the hydrological model to assess the future climate change impact on hydrology of the watershed.

\subsubsection{Statistical Downscaling Model}

According to Wilby et al. (2007) empirical downscaling includes developing a numerical relationship between large-scale atmospheric variables (predictors) and local surface variables (predictands). For this study the canESM2 data were takes as predictors and the station data were taken as predictands. The base line data for the base period were from 3 stations in and around the Awata watershed within the range of 30 years (1988-2017). The first 20 (1988-2007) years of data were considered for calibrating SDSM while the remaining 10 (2008-2017) years were used for validation. After calibrating SDSM model, the future climate scenarios (2018-2077) was generated based on the calibrated parameter and large scale predictor (canESM2 predictor) based on the mean of 20 ensembles for both RCP4.5 and RCP8.5 scenarios.

\subsection{Data Quality Checking and Control}

\subsubsection{Consistency test of Precipitation data}

Consistency of time series data was analyzed based on the theory that a plot of two cumulative quantities that are measured for the same time period should be a straight line and their proportionality unchanged, which is represented by slope. Therefore, the inconsistency of the record was done by the double-mass curve technique. This technique is based on the principle that when each recorded data comes from the parent population, they are consistent. The double mass curve technique was plotted by using the annual cumulative total rainfall of the station under the study as ordinate (Y-axis) and the average annual cumulative total of neighboring stations as abscissa (X-axis). Significant change observed in the system of the curve was, corrected by following equation 1:

$\mathrm{P}_{\mathrm{x}}=\mathrm{P}_{\mathrm{X}} * \frac{\mathrm{M}}{\mathrm{M}}$

where: $-\mathbf{P}_{\mathbf{x}}=$ Corrected precipitation at station $\mathrm{x}$

$\mathbf{P}_{\mathbf{x}}=$ Original recorded precipitation at station $\mathrm{x}$

$\mathrm{M}^{\prime}=$ Corrected slope of the double mass curve

$\mathrm{M}=$ Original slope of the double mass curve

\subsubsection{Homogeneity test}

The second step of the quality control process involved a homogeneity analysis. In this particular study, due to its lower demands in application and interpretation the homogeneity of annual rainfall was tested using XLSTAT.

\subsubsection{Bias correction method of downscaled climate data}

Bias correction compensates for any tendency to over or under estimates the mean of the conditional process by the downscaling model. This parameter is set to 1 (default value) for maximum and minimum temperature since 
the process is non-conditional whereas for precipitation this parameter can be adjusted in order to match the mean of the conditional process and was set to 0.96

\subsection{Data preparation for model input}

The HBV and Gr4J models require daily rainfall, temperature, Daily and average monthly potential evapotranspiration, stream flow (for calibration) and catchment characteristics of the study area. The average areal rainfall was estimated by multiplying the rainfall amount of each station with its area of polygon and the sum of these products was divided by the total area of the catchment (i.e., Thiessen polygon involves by assigning relative weights to the rainfall stations to compute the areal depth of rainfall over the watershed).

\subsection{Hydrological Modeling}

To simulate the stream flow of the watershed, HBV-Light and GR4J models were used. The HBV (Hydrologiska Byrans Vattenbalansavdelning)-Light hydrology model is a widely used conceptual model Seibert (2005). According to (Perrin et al., 2003), the GR4J daily model is one of the simple daily lumped conceptual rainfallrunoff models. Both models compute runoff from observed daily rainfall, daily temperature, long-term monthly potential evapotranspiration and runoff data. The daily areal rainfall (2003-2017) was calculated by Thiessen polygon method. Potential evapotranspiration for the study area was estimated by the FAO Penman-Monteith method. The total period of the data that was used for this specific study was 15 years. From this period by using split sample technique $2 / 3$ rd of the data (2003-2012) were used for calibration and the remaining $1 / 3$ rd of the data (2013-2017) were applied for validation.

\subsection{Model Performance Criteria}

For this particular study, two model simulation performance criteria namely Nash and Sutcliffe efficiency (NSE) and Coefficient of determination $\left(\mathrm{R}^{2}\right)$ were used. The Nash-Sutcliffe coefficient of efficiency (NSE) and coefficient of determination $\mathrm{R}^{2}$ are estimated by:

$$
\begin{array}{cc}
\text { Nash-Sutcliffe efficiency(Reff }) & 1-\frac{\sum\left(\mathrm{Q}_{\mathrm{obs}}-\mathrm{Q}_{\text {sim }}\right)^{2}}{\sum\left(\mathrm{Q}_{\mathrm{obs}}-\overline{\mathrm{Q}_{\mathrm{obs}}}\right)^{2}} \\
\text { Coefficient of Determination }\left(\mathrm{R}^{2}\right) & \frac{\left(\sum\left(\mathrm{Q}_{\mathrm{obs}}-\overline{\mathrm{Q}_{\mathrm{obs}}}\right)\left(\mathrm{Q}_{\mathrm{sim}}-\overline{\mathrm{Q}_{\mathrm{sim}}}\right)\right)^{2}}{\sum\left(\mathrm{Q}_{\mathrm{obs}}-\overline{\mathrm{Q}_{\mathrm{obs}}}\right)^{2} \sum\left(\mathrm{Q}_{\mathrm{sim}}-\overline{\mathrm{Q}_{\mathrm{sim}}}\right)^{2}}
\end{array}
$$

where: $=$ observed runoff; $=$ simulated runoff; $\overline{Q_{\text {obs }}}, \overline{Q_{\text {sım }}}=$ mean observed and simulated runoff.

\section{Results and Discussion}

\subsection{CanESM2 output Downscaling for the Future Climate Scenarios}

Climate scenarios for future periods (2018-2047) and (2048-2077) have been developed for two emission scenarios of canESM2 RCP4.5 and RCP8.5 based on the mean of 20 ensembles.

\subsubsection{Minimum temperature}

As shown in Figure (2), the projected average monthly minimum temperature result implies increasing trend under both RCP scenario for the future period (2018-2047) and (2048-2077). The RCP4.5 scenario suggests there is an increment of the minimum temperature from $1.05^{\circ} \mathrm{C}$ to $1.82^{\circ} \mathrm{C}$ for near-term $(2020)$ and $1.06^{\circ} \mathrm{C}-2.30^{\circ} \mathrm{C}$ for midterm (2050) from the baseline period. And under RCP8.5 scenario shows from baseline period the minimum temperature expect to increase from $1.51^{\circ} \mathrm{C}-2.3^{\circ} \mathrm{C}$ for near-term and $1.64^{\circ} \mathrm{C}-2.94^{\circ} \mathrm{C}$ for mid-term respectively.

\subsubsection{Maximum temperature}

As it shown in Figure 3, the mean monthly maximum temperature shown generally an increase trend for future period (2018-2047) and (2048-2077) under both RCP4.5 and RCP8.5 scenario. The RCP4.5 scenario suggests the monthly maximum temperature will increases from $0.32^{\circ} \mathrm{C}$ to $1.41^{\circ} \mathrm{C}$ for near-term $(2020)$ and $0.37^{\circ} \mathrm{C}-1.66^{\circ} \mathrm{C}$ for mid-term (2050) from the baseline period. And also RCP8.5 scenario shows from baseline period the monthly maximum temperature will increases from $0.89^{\circ} \mathrm{C}-1.90^{\circ} \mathrm{C}$ for near-term and $1.17^{\circ} \mathrm{C}-2.25^{\circ} \mathrm{C}$ for mid-term respectively.

\subsubsection{Areal precipitation}

As it depicted in Figure 4, the mean monthly precipitation shows both increasing and decreasing trend for both RCP4.5 and RCP8.5 scenario for future period (2018-2077).

Under RCP4.5 the monthly precipitation decreases pattern indicates in January, May, October, November and December up to $(9.1 \%-34.4 \%)$ and (12.4\% -33.2\%) in near (2018-2047) and mid-term (2048-2077) respectively.

As shown in Figure 4, under RCP8.5 the projected change shows mean monthly precipitation increasing pattern principally from February-May and June-September in between (2.9-101.3\%) in near-term and (5.1-99.7\%) in mid-term scenarios. Nevertheless under RCP8.5 monthly precipitation distribution indicates a decreasing pattern in January, May, October, November and December up to (11.6-37.8\%) in near-term and (16.3-39.8\%) in midterm future times. 

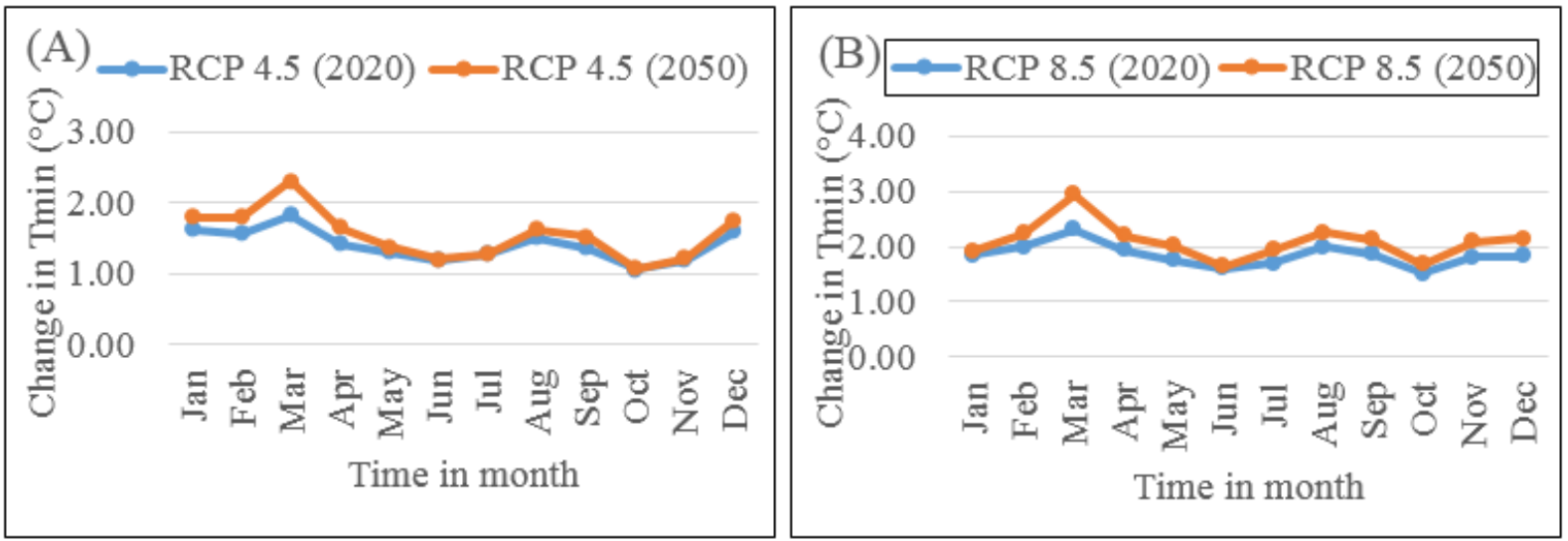

Figure 2. Projected changes in average monthly minimum temperature for near-term scenario (2018-2047) and mid-term scenario (2048-2077) under RCP 4.5 (A) and RCP 8.5 (B) respectively
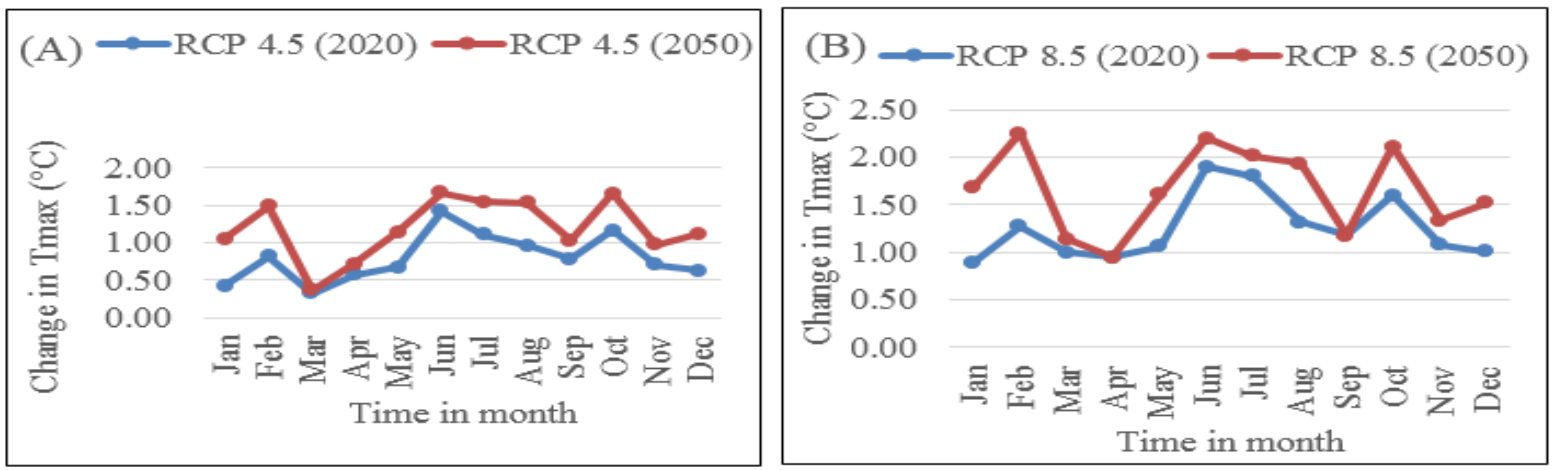

Figure 3. Projected changes in average monthly maximum temperature for near-term scenario (2018-2047) and mid-term scenario (2048-2077) under RCP 4.5 (A) and RCP 8.5 (B) respectively.

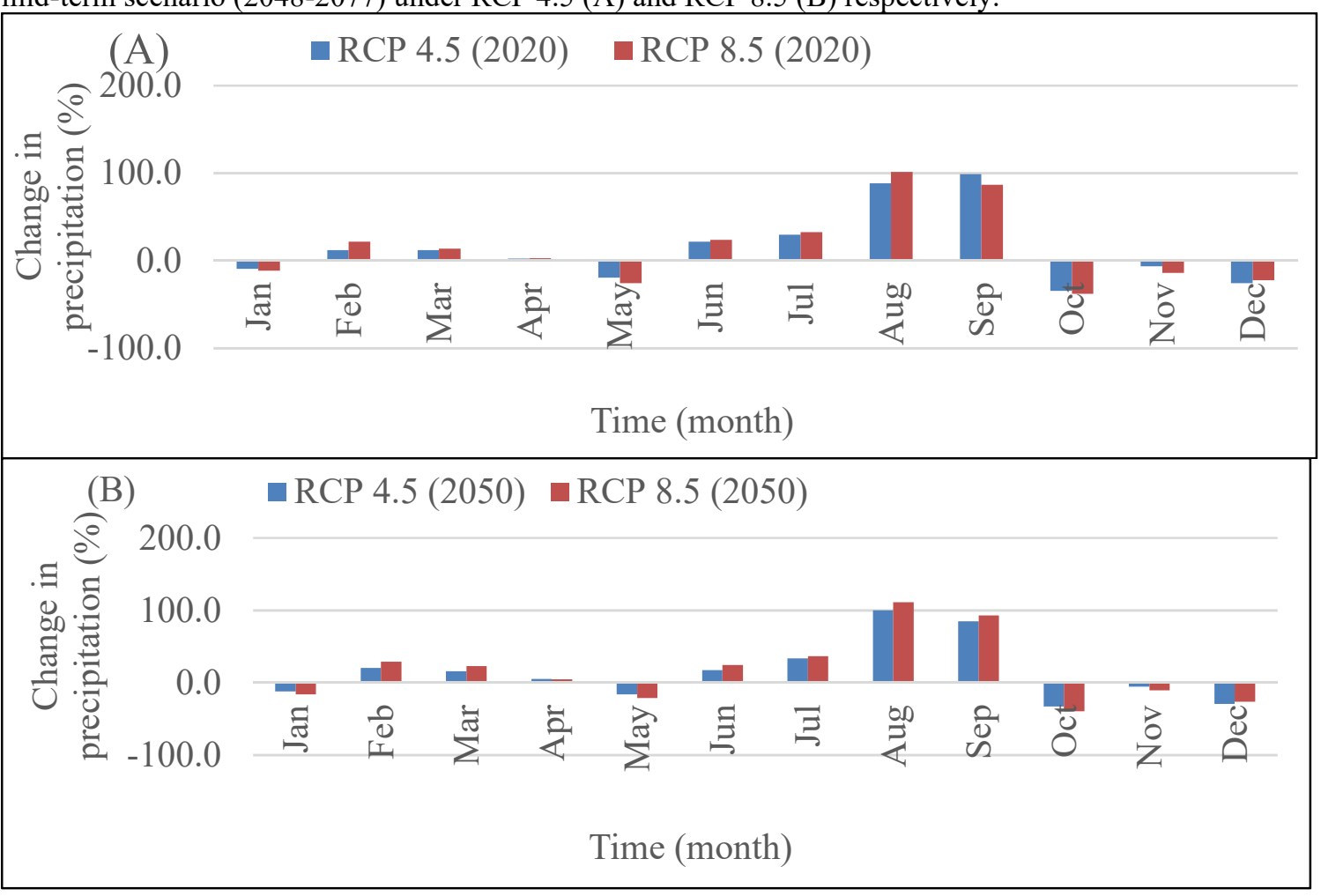

Figure 4.Projected change of average monthly precipitation distribution for near-term (A) and mid-term (B) under RCP 4.5 and RCP 8.5 respectively. 


\subsection{Parameters Sensitivity Analysis}

The parameters sensitivity test was carried out by changing one parameter at a time while keeping the others constant and the effect of changes on the Nash Sutcliffe efficiency and coefficient of determination was considered.

\subsection{Hydrological Model Calibration and Validation}

The calibration and validation of HBV-Light and GR4J models were implemented by using split sample technique (2003-2012) data for calibration and the remaining (2013-2017) data for validation. Calibration was done manually by optimizing the model parameters in each subroutine that have a significant effect on the performance of the model using observed stream flow. Based on this, several runs were made to select the most optimum parameter set in order to match the observed discharge with simulate discharge.

The result of each run was evaluated in different ways including visually inspecting and comparing the calculated and observed hydrograph. The overall performances of both models were good, at monthly time scale; on calibration $\left(\mathrm{R}^{2}=0.87\right.$ and NSE $\left.=0.78\right)$ and validation $\left(\mathrm{R}^{2}=0.85\right.$ and $\left.\mathrm{NSE}=0.80\right)$ with HBV Light whereas, calibration $\left(\mathrm{R}^{2}=0.81\right.$ and $\left.\mathrm{NSE}=0.72\right)$ and validation $\left(\mathrm{R}^{2}=0.84\right.$ and $\left.\mathrm{NSE}=0.75\right)$ for GR4J model. Generally speaking, the results show that the both models can reproduce historical daily discharge with an acceptable accuracy. The calibration and validation result of HBV Light and GR4J models are shown in Figure 5 and Figure 6. NSE and R ${ }^{2}$ were calculated from simulated discharge values and the available observed runoff for the simulation time period. Under both hydrological models during monthly calibration and validation the simulated stream flow is not exactly corresponding to monthly projected precipitation, this might be due to the fact that run-off and precipitation do not formed at the same time.

\subsection{Model Performance Evaluation}

The calibration and validation results in (Figure 5 and 6) show that there is good agreement between observed and simulated values in monthly scale of calibration periods for both models. The percent of error of the models simulation from observed flow at Awata watershed were $15.6 \%$ and $18.2 \%$ for simulation done with HBV light and GR4J models respectively. The NSE and $\mathrm{R}^{2}$ statistical performance indicators showed that the HBV light model performed better than the GR4J model during calibration and validation (Figure 5 and 6).

As shown in figure 5 and 6, the simulated stream flow for the Awata watershed using the HBV light reveals a higher fraction of simulated discharge and a low percentage of error than GR4J model.

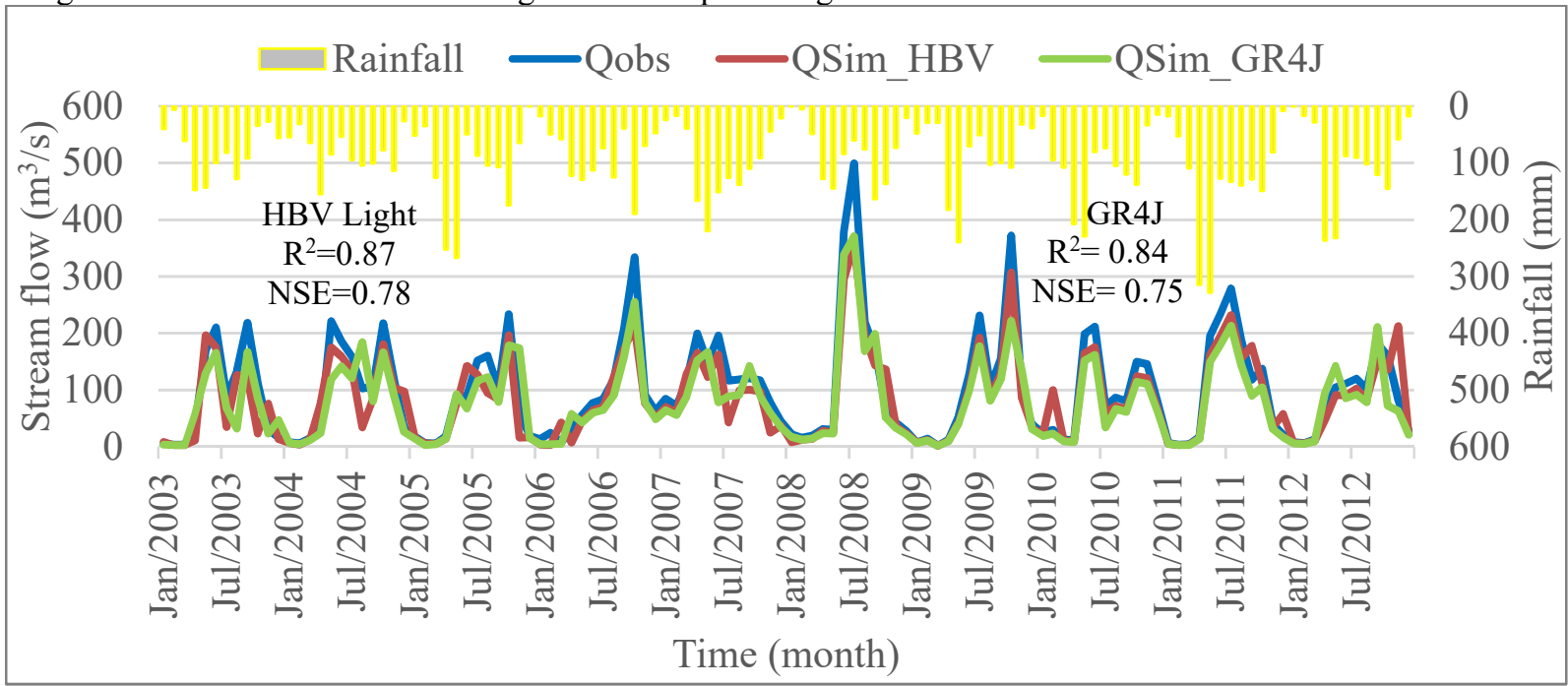

Figure 5. Monthly observed vs. simulated discharge hydrograph of Awata watershed for the HBV-light and GR4J models during calibration period (2003-2012). 


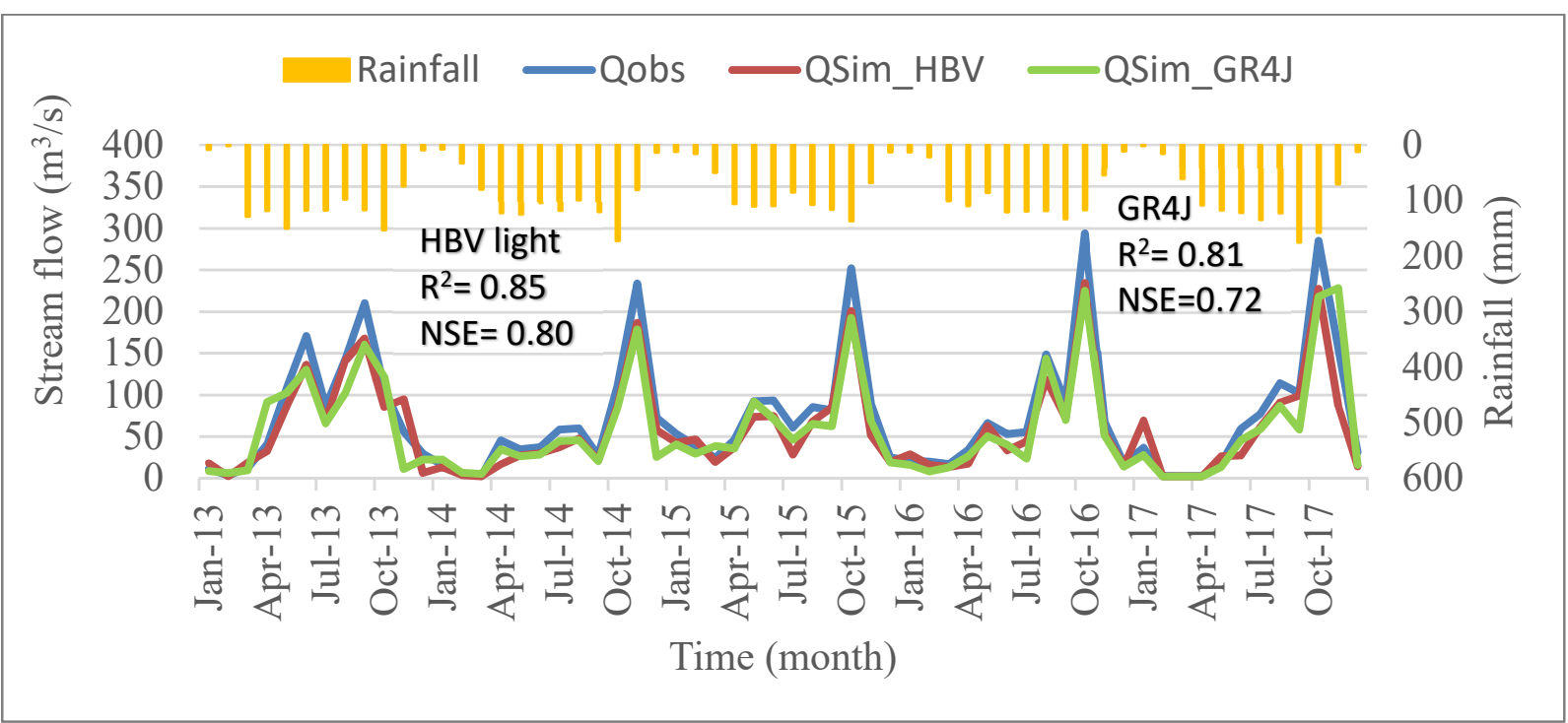

Figure 6. . Monthly observed vs. simulated discharge hydrograph of Awata watershed for the HBV-light and GR4J models during validation period (2013-2017).

\subsection{Model Results Comparison and Impact of Climate Change on Stream Flow under Future Scenarios}

The impacts of climate change was analyzed taking the 2003-2017 flow as the baseline flow compared with the future flows for the 2020s(2018-2047) and 2050s(2048-2077). Based on this, the hydrological impact of Awata watershed was analyzed using HBV and GR4J models with respect to two 30 years period centered on 2020s and 2050s. The simulation result for two future time horizons is summarized in figure 7(A) and (B). As it can be seen from (Figure 2 and 3), the overall results (2018-2077) for average annual total flow volume showed an increasing trend for both RCP 4.5 and RCP 8.5 simulated with both models as compared to base period.

HBV light indicate the percentage increment of total average annual flow volume $7.3 \%(2018-2047)$ and $7.0 \%$ (2048-2077) for RCP 4.5 scenario, and For RCP 8.5 scenario, the increment ranges between $7.7 \%$ (2018-2047) to $7.9 \%(2048-2077)$ as shown in (Figure 7) (A) and (B).

The GR4J model indicates the percentage increment of total average annual flow volume $6.4 \%(2018-2047)$ and 6.6\% (2048-2077) for RCP 4.5 scenario, and For RCP 8.5 scenario, the increment ranges between $6.2 \%(2018$ 2047 ) to $7.6 \%$ (2048-2077) (Figure 7) (A) and (B). Increase in average total annual flow volume is observed for periods which show a corresponding increase in mean annual precipitation during scenario developments.

Seasonally, both models indicate the average total flow volume increases in Kiremet season (June- September) and decrease in Bega season (October- January) for future two time horizon comparing with base period. The percentage change of ranges between $+24.7 \%(2018-2047)$ to $+25.6 \%(2048-2077)$ for simulation with the HBV model in Kiremet season under RCP8.5. However, simulation with GR4J model indicates that the percentage change $+22.9 \%(2018-2047)$ to $+25.3 \%(2048-2077)$ in Kiremet season under RCP8.5 emission scenario. The percent of increment for RCP 8.5 (high emission) scenario was higher than RCP4.5 (medium emission) scenario for both hydrological models. Simulation with both models shows that almost no change in Belg season.

On monthly basis, both models indicate decrease trend in months of January, May, October and December; and increased trend in months of February, March, April, June, July, August and September throughout the future two time horizon for both RCP4.5 and RCP8.5 scenarios as compared with base period (Figure 7)(A) and (B).

According to figure 7 (A), in 2020s, HBV light model indicates a monthly decrease up to $-4.7 \%$ to $-26.6 \%$ and increase up to $+5.7 \%$ to $+30.5 \%$ for RCP4.5 and likely for RCP 8.5 scenarios, a monthly decrease up to $-5.9 \%$ to $-35.1 \%$ and increase up to $+8.3 \%$ to $+33.9 \%$. However, the GR4J model indicates a monthly decrease up to $6.4 \%$ to $-29.4 \%$ and increase up to $+8.9 \%$ to $+29.9 \%$ for RCP 4.5 , and for RCP8.5 scenarios, a monthly decrease up to $-7.4 \%$ to $-34.6 \%$ and increase up to $+7.0 \%$ to $+34.0 \%$ respectively.

As can be observed from figure 7 (B), in 2050s both hydrological models exhibited a decrease and increase in monthly stream flow for both RCP 4.5 and RCP 8.5 scenarios. HBV light model indicates a monthly decrease up to $-6.0 \%$ to $-30.0 \%$ and increase up to $+10.4 \%$ to $+31.9 \%$ for RCP4.5 and under RCP 8.5 scenarios, a monthly decrease up to $-6.2 \%$ to $-38.3 \%$ and increase up to $+10.2 \%$ to $+34.4 \%$. On the other hand, the GR $4 \mathrm{~J}$ model indicates a monthly decrease up to $-6.6 \%$ to $-30.6 \%$ and increase up to $+10.4 \%$ to $+31.9 \%$ for RCP 4.5 and under RCP 8.5 scenarios, a monthly decrease up to $-8.1 \%$ to $-35.9 \%$ and increase up to $+9.2 \%$ to $+35 \%$; However, the change is higher for the GR4J than for the HBV-Light model as shown in Figure 7 (A) and (B). These results indicate that different hydrological models provide different stream flow results for a given input as a result of differences in 
model structures.

Moreover the two models indicate the lowest percentage decrease in the month of January and the highest percentage of decrease in the month of October in future near term and mid-term time horizon for both RCP 4.5 and RCP 8.5 scenario. On the other hand both models indicates the lowest percentage of increase in the month of February and the highest percentage of increase in September for both RCP 4.5 and RCP8.5 scenario. These results agree with Shanka (2017) who carried out research in Gidabo River basin which is found in Southern part of Ethiopia using GCM out including HadCM3. This finding is also harmonious with the findings of Kassa (2014).

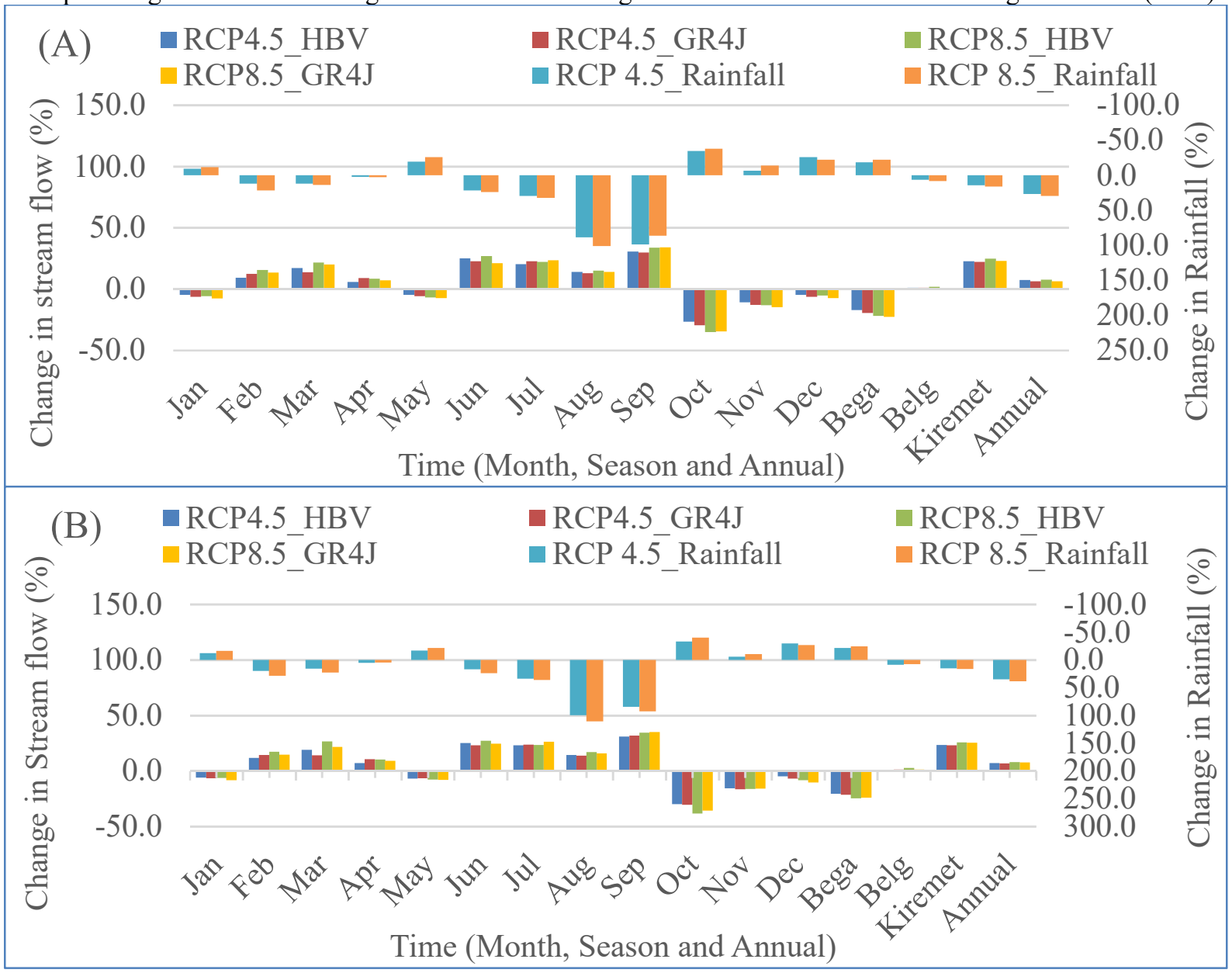

Figure 7.Projected change of mean monthly Stream flow in near-term (2018-2047) (A), and mid-term (2048-2077) (B) from the baseline period (2003-2017) in Awata watershed.

\section{Conclusion and Recommendation}

As the result indicates the mean monthly minimum temperature would increase in the range of $+1.05^{\circ} \mathrm{C}$ to $+1.82^{\circ} \mathrm{C}$ for near-term $(2018-2047)$ and $+1.06^{\circ} \mathrm{C}$ to $+2.30^{\circ} \mathrm{C}$ for mid-term $(2048-2077)$ from the baseline period under $\mathrm{RCP} 4.5$. Under RCP8.5 scenario also shows from baseline period the minimum temperature was increased in $+1.51^{\circ} \mathrm{C}$ to $+2.3^{\circ} \mathrm{C}$ for near-term and $+1.64^{\circ} \mathrm{C}$ to $+2.94^{\circ} \mathrm{C}$ for mid-term respectively. The mean monthly maximum temperature was also expected to increase in the range of $+0.32^{\circ} \mathrm{C}$ to $+1.41^{\circ} \mathrm{C}$ for near-term $(2018-2047)$ and $+0.37^{\circ} \mathrm{C}$ to $1.66^{\circ} \mathrm{C}$ for mid-term $(2048-2077)$ from the baseline period for RCP4.5 scenario. For RCP8.5 scenario shows from baseline period the maximum temperature was increased in the range of $+0.89^{\circ} \mathrm{C}$ to $+1.90^{\circ} \mathrm{C}$ for nearterm and $+1.17^{\circ} \mathrm{C}$ to $+2.25^{\circ} \mathrm{C}$ for mid-term respectively.

The result of Statistical Downscaling Model for the future scenario (RCP4.5 and RCP8.5) on monthly and seasonal basis indicate that precipitation does not show systematic increase or decrease. Precipitation increase in some months and decrease in other months for both RCP4.5 and RCP8.5 scenario in all future time horizon (20182077). However in the main rainy season, Kiremet (June-September) revealed increased trend with highest increased observed up to a maximum of 16.3\% (2050) for RCP 8.5 scenario and $15.3 \%$ (2050) for RCP 4.5 scenario. In Bega season both RCP4.5 and RCP8.5 scenario indicate a decreasing pattern of precipitation in the two future time horizon comparing with the base period with the maximum value of $-21.4 \%(2050)$ and $-24.7 \%(2050)$ for RCP4.5 and RCP8.5 respectively. Overall annual precipitation shows an increasing trend for both RCP4.5 and 
RCP8.5 scenario with the percent of increment up to $26.8 \%$ and $35.1 \%$ at near and mid-term respectively.

Two conceptual hydrological models namely HBV light and GR4J were selected and tested for the hydrological characteristics of Awata watershed. The two models were run for calibration (2003-2012) and validation (2013-2017). On monthly based the results of HBV-Light shows that the model is able to reproduce discharge with good performance $\left(\mathrm{R}^{2}=0.87, \mathrm{NSE}=0.84\right)$ and $\left(\mathrm{R}^{2}=0.85, \mathrm{NSE}=0.80\right)$ during calibration and validation respectively. On the other hand GR4J model results shows $\left(\mathrm{R}^{2}=0.87, \mathrm{NSE}=0.74\right)$ and $\left(\mathrm{R}^{2}=0.81, \mathrm{NSE}\right.$ $=0.73$ ) during calibration and validation respectively.

The models and model output used in this study processed a certain level of uncertainty. Hence, the result of this research should be taken carefully and considered as an indicative prediction of the future and further researches should be expected by considering land use change in addition to climate change. The result of this study is based on the output of single GCM and only two emission scenarios (RCP4.5 and RCP8.5). However, it is recommended to use the different GCM outputs and emission scenarios to compare the result of different models and explore a wide range of climate change scenario that would result different hydrological impacts. Meanwhile, the GCM was downscaled to a watershed level only using statistical downscaling models which is the regressionbased model, even though other methods exist which are used for impact assessment. Thus, this study should be extended in the future considering other downscaling methods. When long records of rainfall and runoff are available, even though there simulation capacity are slightly dissimilar the conceptual models HBV light and GR4J can be successfully calibrated and used both for simulation and for real time stream flow forecasting.

\section{REFERENCES}

Arora, V.K. and Boer, G.J., 2001. Effects of simulated climate change on the hydrology of major river basins. Journal of Geophysical Research: Atmospheres, 106(D4), 3335-3348.

Conway, D. and Schipper, E.L.F., 2011. Adaptation to climate change in Africa: Challenges and opportunities identified from Ethiopia. Global Environmental Change, 21(1): 227-237.

IPCC (Inter governmental Panel on Climate Change) 2013. Summary for Policy makers. In Climate Change: The Physical Science Basis; Contribution of Working Group I to the IPCC Fifth Assessment Report Climate Change; Cambridge University Press: Cambridge, UK; New York, NY, USA.

IPCC (Inter governmental Panel on Climate Change). 2001: Climate Change 2001. The Scientific Basis. Contribution of Working Group I to the Third Assessment Report of the Intergovernmental Panel on Climate Change [Houghton, J.T., Y. Ding, D.J. Griggs, M. Noguer, P.J. van der Linden,X. Dai, K.Maskell, And C.A. Johnson (eds.)]. Cambridge University Press, Cambridge, United Kingdom and New York, NY, USA, 881

IPCC (Inter governmental Panel on Climate Change). 2007. Summary for Policymakers. In: Climate Change 2007. The Physical Science Basis. Contribution of Working Group I to the Fourth Assessment Report of the Intergovernmental Panel on Climate Change [Solomon, S., Qin, D., Manning, M., Averyt, K. and Marquis, M. (Eds.)]. Cambridge University Press, Cambridge, United Kingdom and New York, NY, USA.

Kassa T., 2014. Assessment of climate change impacts on water availability in Gidabo River basin, Ethiopia.

McSweeney, C., New, M. and Lizcano, G., 2010. UNDP (2008) Climate change country profiles: Ethiopia.

Perrin, C., Michel, C. and Andréassian, V., 2003. Improvement of a parsimonious model for stream flow simulation. Journal of hydrology, 279(1-4), 275-289.

Seibert, J., 2005. HBV Light version 2 User's Manual. November 2005 Stockholm University, Department of Physical Geography and Quaternary Geology. Available at http://peoplesu.se/ jseib/HBV/HBV_manual_2005.pdf

Shanka, A. S. 2017. Evaluation of Climate Change Impacts on Run-Off in the Gidabo River Basin: Southern Ethiopia. Environment Pollution and Climate Change, 01(03), 1-6. https://doi.org/10.4172/2573458X.1000129

Tao J., Yongqin D., Chong-yu X., Xiaohong C., Xi, C. and Vijay P., Rientjies T., 2OO7. Modelling in Hydrology, ITC lecture books. 233.

Wilby, R. L. and Dawson C. W., 2007. SDSM 4.2 a decision support tool for the assessment of regional climate change impacts, User Manual. Department of Geography, Lancaster University, UK.

World Bank. 2015. Regional dashboard: poverty and equity, Sub Saharan Africa. http://povertydata.worldbank.org/poverty/region/SSA. 